force was in the direction of the wound when defecation took place, consequently the healing of the trench-shaped wound formed a natural prolongation of the rectum ending at the skin.

Whittlesea, Cape Colony.

\section{DIFFUSE HAMATOMA OF THE BACK; DEATH.}

By G. Oscar JACOBSEN, M.R.C.S., L.R.C.P. LoND.

I was called on March 18th to see T. E-, who, I was informed, had on the previous night hurt his back in a fall. On arriving I found that the patient, a man aged fifty-eight, seemed to be in considerable pain, and on examination of the back discovered a large swelling, which corresponded roughly in site and size to the right scapula. The tumour appeared to be fluid, as there were distinct evidences of fluctuation. There was no discolouration of the skin. From the history $I$ took it to be a hæmatoma, and pre scribed a lead lotion, rest, and sedatives. I was unable to obtain ice. The patient, I was told, had got up from the sofa, and was crossing the room, and during the momentary absence of his wife was seized with an attack of giddiness, and had fallen with all his weight with the right side of his back against the sharp jamb of the door-post. I had been atterding him for kidney disease, and what I took to be Ménière's disease, the patient complaining of constant attacks of vertigo associated with one-sided deafness. The next day, the 19th, the man seemed no worse, but the swelling had increased. The third day he seemed in a gocd deal more pain, and the swelling now extended upwards under the muscles of the right side of the neck nearly as high as the mastoid process, downwards to the small of the back, and had, moreover, now become very much discoloured. The next night $I$ was sent for again, and found the patient in a very bad way, delirious, with running pulse and great dyspncea-in fact, moribund, and he died the next morning, the $23 \mathrm{rd}$, at 5 A.M., a little over five days from the time of the accident. A necropsy was ordered by the coroner, which I made about thirty hours after death. On inspection there was found to be considerable swelling on the right side from the mastoid process to the lumbar region. This was dis tinctly fluctuating, and there was very great discolouration of the skin, not due to post-mortem changes. On opening the chest the first thing noticed was infiltration of all the pectoral muscles of the right side with blood. On dissecting them carefully back this was found to become more and more intense, and after reaching a point just behind the mid-axillary line there was found underneath the latissimus dorsi a huge cavity which contained over three pints of semi-fluid and coagulated blood. The intercostal muscles were sodden with blood, and at one point seemed breaking down into the pleural cavity. The right pleural cavity contained a fair quantity of blood-stained fluid, and towards the base some very recent lymph, which also was found on the surface of the base of the lung. The lungs appeared healthy, and the other organs appeared fairly healthy, with the exception of the liver, which was somewhat enlarged, and the kidneys, which were granular, with diminished corbex, and the capsule very adherent. There was atheroma of the aorta and thickening of the aorbic valves.

This case I think interesting and worthy of record, owing to the comparatively slight in jury - namely, the fall against the door-post-the large amount of blood effused, and the considerable length of time elapsing before death. The extent of the bremorrhage I attributed to the brittle state of the arteries consequent upon the patien t's kidney disease. Ashwell, near Baldock.

FOOT-AND-MOUTH DISEASE IN KENT.-The footand-month disease in the Sittingbourne district is, it is stated, increasing, and threatens to become epidemic. The third outbreak in the course of a few days was reported on the 16 th inst., when it was discovered that the malady had made its appearance among a flock of about 150 sheep on Oakwood Farm, near Sittingbourne, belonging to Mr. G. H. Dean. This latest outbreak has had the effect of extending the boundary of the infected district. This was apparent on Good Friday, when a large number of pedestrians who attempted to pass through Gore Court Park found several of the footpaths closed to the public and guarded by police.

\section{a eftitrot}

\section{HOSPITAL PRACTICH, BRITISH AND FOREIGN.}

Nulla autem est alia pro certo noscendi via, nisi quamplurimas et mcr. borum et dissectionum historias, tum aliorum tum proprias collectas habere, et inter se comparare.-Morgagin De Sed. et Caus. Horb., lib. iv. Procemium.

WESTMINSTER HOSPITAL.

ENTERIC FEVER; RIGHT HEMIPLEGIA WITH APHASIA: RELAPSE ; DEATH.

(Under the care of Dr. DoNKIN.)

THIs case is placed on record on account of the excep. tional accurrence of hemiplegia in connexion with enteric fever. In connexion with this case Dr. Donkin observed that some few cases have been reported, but mostly without necropsies. Two cases in children with recovery were recorded by Dr. Gee and Dr. Cayley respectively in the Medical Times and Gazette for 1878, vol. i. The blocking of the cerebral arteries is usually put down, according to inference from probability, to an embolic cause, and where no cardiac abnormality is demonstrated or indicated the embolism is supposed to arise from a broken-up thrombus in the left heart. In this case there was nothing noteworthy in the heart's structure or contents. We have probably to choose between thrombosis in situ or some temporary clotting in the heart's cavities leading to embolism for explanation of the arterial blocking which was discovered both in the brain and the lung. It seems much more probable that both the clots found were produced in situ, and that their cause was the same-viz., depression of the circulatory force from the long and severe pyrexia, which was evidenced by continuous dicrotism of the pulse and great weakening or silence of the first sound of the heart. Direct impairment of the nutrition of the arteries was a part of the profound effect of continued and especially of enteric fever on the tissues generally, and morbid changes in the blood were probably important co.factors with the weakened hearb in producing the result. It must be remem. bered that the patient had an extensive bronchitis with much dyspnoea, causing excessive stress on a heart already overworked and probably dilated in the course of the fever. In this context Dr. Donkin called attention to a case recorded by Dr. J. Abercrombie where sudder left hemi. plegia occurred in a boy of six years old with diphtheria, the necropsy showing thrombosis of the right middle cerebral artery without valvular heart disease or evidence of embolism. The account of the case is abstracted from notes furnished by Mr. Gossage, house physician.

The subject of this record, aged thirty, had been nursing two cases of enteric fever in a house where the drains were believed to be very defective. One of these cases died after a severe course of the fever with profuse fetid diarrboa. The nurse began to feel ill while at her duties a fortnight before admission to hospital on Dec. 2 nd. On Nov. 28 th she had severe headache, and on the following two days suffered from pains all over, and shivered repestedly. On Dec. 2nd there were slight cough, slight diarrboea, and some vomiting. She was the subject of chronically enlarged glands in the neck, which had been getting larger during the three weeks before admission; had bad "strumous conjunctivitis" two years before; and attacks of influenza in January, 1890, and May, 1891, the last being severe. On admission, the temperature was $104^{\circ} \mathrm{F}$, , and there was some distension, with great pain and tenderness of the abdomen. From this date to the 15th the temperature rangea between $104^{\circ} 8^{\circ}$ and $102^{\circ}$, being usually over $103^{\circ}$, and there was much abdominal pain, occasional vomiting, and abundant eruption. After five days' constipation, 2 simple enema was given on the 8th, and subsequently there were from one to three semi.solid or solid motions on most days till the 15th, when fairly marked morning remissions of temperature set in. On the 15th bronchitic signs were heard all over the chest. The bronchitis became severe, with considerable dyspn œe, for several days, and the temperature ranged generally between $101 \cdot 5^{\circ}$ and $103^{\circ}$, occa- 
sionally rising to $104^{\circ}$, until the $22 \mathrm{ad}$. After this the vemperature gradually fell and the bronchitis decreased, until at the end of the month pyrexia ceased and the signs of bronchitis disappeared. On the 3 lst the patientcomplained of somewhat severe pain in the head. Her bowels had not acted for several days, and an enema was ordered on Jan. 1st. The nurse, who was about to administer the enema at is P.M., found the patient with much impaired consciousness and unable to articulate; she had been apparently asleep for an hour previously. On examination there was drooping of the left eyelid and considerable paralysis of the right arm and leg. She could hear well and apparently understood what was said to her, putting out her tongue - which was seemingly protruded straight-very slowly. Swallowing was somewhat difficult, and urine was passed in bed. Daring the next few days the paralysis became complete, and there was considerable loss of sensibility in the affected limbs; the breathing was somewhat laboured, and urine and freces were passed in bed. On the 4 th the temperature arose slightly; on the 5 th it was $102^{\circ}$ in the evening; on the 8th there were rose spots, loose motions, and some vomiting. The eruption and diarrhcea continued, and on the 14 th the evening temperature was $104^{\circ}$, the pulse rose to 160 , and the breathing became frequent and very laboured. On the 15 th the pulse was running, the temperature rose to $105^{\circ}$, and the patient died at midnight.

The necropsy was made forty hours after death by Dr. Hebb. The brain substance was pallid, the sulci deep. The left carotid was distended with a softish dark clot which extended to its principal branches, the middle cerebral being apparently most affected, but the clot was confined to the Sylvian fissure. (Owing to certain conditions of the postmortem examination the lower part of the carotid was not examined.) The supply area of the middle cerebral was extremely disorganised, the softened parts being the left corpus striatum, the island of Reil, the operculum, the anterior fourth of the upper internal temporo-sphenoidal convolution, and the wall of the lateral ventricle in more than its front third. The corpus striatum was of a greenishyellow hue, and only kept in position by its attachment posteriorly to the optic thalamus. Elsewhere the surrounding nerve tissue was broken down flocculent detribus. This disorganisation affected the whole of the anterior cornu and the wall of the ventricle as far back as the front of the optic thalamus. The optic thalamus was somewhat softer than normal, and chiefly affected in its outer front part. The resí of the cerebrum, the cerebellar pons, and medulla were, except that the puncta vaseulosa were large, not noteworthy. The vessels of the pia mater were to the naked eye normal. The pleura was smooth. The bases of both lungs were much congested and very friable. About the centre of the anterior edge of the left lower lobe was a faintly yellow infarct, abont the size of a large walnut, having somewhat the appearance and consistence of grey hepatisation. The pulmonary arteriole supplying this was thrombosed by a dark, softish clot. There was evidence of general bronchitis. The heart and peritoneum were normal. The mesenteric glands were very large and soft, and much blood-stained. The spleen was large, tense, and turgid; parenchyma very soft and quite black. Extensive "typhoid" vlceration was found in the ileum, mostly healed, but: two large and recent ulcers; also some very small recent ulcers in the ascending colon.

\section{SHEFFIELD PUBLIC HOSPITAL AND} DISPENSARY.

WIVE CASES OF INTRAVENOUS INJECTION OF SALINE FLUID FOR HEMORRHAGE AND COLLAPSE. ${ }^{1}$

(Under the care of Mr. R. J. Pye-Smith.)

THE following cases, all of them of extreme gravity, have recently been treated at the Sheffield Public Hospital and Dispensary by a method which deserves to have more attention called to it. In THE LANCET of Sept. 12th, 1891, Mr. Arbuthnot Lane related a remarkable case in which he had saved the life of a child moribund from hæmorrhage by the intravenous injection of three pints and a half of saline fluid. Although the intravenous injection of watery fluid is as old as transfusion of blood, having been practised by Sir Christopher Wren in 1656 and being mentioned by Libavius in $1615,{ }^{2}$ it has not often been used in such large quantities as those employed by Mr. Lane, except in cases of cholera, in which disease it was very successfully employed in doses up to four pints by Dr. Little at the London Hospital in 1848-49, and again by Mr. L. S. Little in 1866-67. The quantity of fluid used is, however, one of the most essential points in the intravenous injection of saline fluid. However valuable and necessary the red corpuscles and the nutritive constituents of the blood may be, it is not their diminution that gives rise to the immediate danger in cases of acute hæmorrhage. The real cause of death is a mechanical one, and consists in the loss of volume in the circulating fluid, which must, within certain limits, be proportional to the capacity of the vascular system. These limits are practically defined by the action of the vaso-motor apparatus, which, within them, automatically regulates the tension throughout the arterial system; but as soon as the limit is over-reached in the way of de. pletion, the regulating power which adapts the tension of the vessels to their contents ceases, the toneless arteries then fail in their share in the propulsion of the blood, and-the capillaries, the veins, and the heart being each affected in its own way--the circulation flags, and ultimately ceases. This fatal condition is reached when the quantity of blood is suddenly reduced to between three-quarters and half the normal or actually present amount in the body, and therefore long before death would have resulted from the diminished quantity of red corpuscles or from loss of nutritive material in the blood. It is not the composition of the blood but its bulk that is at fault, and the resulo is not oxygen starvation or tissue starvation, but failure of circulation. The rational way to meeb this emergency is the intra-vascular injection of a sufficient quantity of any fluid not injurious to the blood or to any of the tissues of the body. Such a fluid we have ready to hand in "normal saline solution"-i.e., $\frac{3}{4}$ per cent. aqueons solution of sodium chloride. The fluid is prepared by dissolving clean common table salt in clear, recently boiled water in the proportion of a drachm to the pint. It is injected into any convenient vein, at the rate of a pint in ten minutes, at blood heat, and in quantities sufficient to restore fulness to the pulse or to equal the amount of blood lost; and as in cases of death from sudden hæmorrhage the amount lost is usually from three to four pints, that should probably be about the quantity employed. The apparatus Mr. Pye-Smith has employed for injecting has been, except in the firsb case, a simple glass syringe, as recommended by $\mathrm{Mr}$. Lane, to the nozzle of which a T-shaped piece of tubing has been attached, the other arms of which were connected respectively, by means of india. rubber tubing, with the cannula in the vein and the saline solution in a jug. With the help of an assistant to compress the two indiarubber tubes alternately it is quite easy to inject continuously with such an apparatus without danger of injecting air into the vein.

CAsE 1. Gunshot wound of leg; homorrhage; collapse; injection of three pints of saline fuid; amputation of leg; recovery. $-\mathrm{H}$. W-, a carter aged twenty-six, was admitted on Sept. $25 \mathrm{th}, 1891$. He was accidentally shot in the left leg by the discharge of a fowling-piece at a distance of two or three yards, and sustained a severe lacerated wound, with compound comminuted fracture of tibia and fibula. He bled profusely for half an hour before being got to a house, where a handkerchief bandage was tightly applied to the thigh by a priest, and he was sent in a cart to the hospital, a distance of twelve miles. He arrived about three hours after the accident, and was admitted under the care of Dr. Keeling, in whose absence and that of Mr. Thorpe Mr. PyeSmith was called to see the patient. ${ }^{3}$ He found him much blanched and collapsed, with small, weak, and frequent pulse and cold extremities. The man was res less, and complained of pain and thirst. It was evident that the leg required amputation, but the patient seemed quite unfit to undergo such an operation, and Mr. Pye-Smith determined to try the injection of saline fluid before submitting him to it. Meanwhile, bot water bottles were applied to the body, and he was ordered a drachm of brandy with five minims of laudanum every half hour in an ounce of hot water. Ether

2 South's Chelius.

3 Mr. Pye-Smith thanks Dr. Keeling, who was away on his holiday at the time, for leave to report the case, and Mr. Thorpe, who arsived at the hospital half an hour after him, for having kindly left the case in
his hands. 